\title{
Internet Utilization by the Students with Visual Impairment Disabilities
}

\author{
https://doi.org/10.3991/ijet.v14i10.10057 \\ Hanny Hafiar ${ }^{(凶)}$, Priyo Subekti, Aat Ruchiat Nugraha \\ Universitas Padjadjaran, Bandung, Indonesia \\ hanny.hafiar@unpad.ac.id
}

\begin{abstract}
As a millennial generation, teenagers have the need to use the internet in their daily activities. The need to access the internet is also felt by students with visually impaired. Although many various sources of information are still in the form of text, with the help of various types of assistance programs, students with visually impaired can access this information. With the existence of various assistance programs, teenagers with visually impaired can access the internet more unimpeded. Based on this background, the purpose of this research is to find out the use of the internet by students with visually impaired. The results are sequentially stated that the use of the internet includes access to WhatsApp, YouTube, Google, Social Media (Facebook and Instagram), radio streaming, video downloads, music downloads, Map/location identifiers, online shopping and TV streaming to watch football broadcasts. However, there are still a number of obstacles faced by students with visually impaired who still need technological development so that the opportunity for people with visually impaired to access the internet is increasingly open. In addition, directing efforts from related institutions are needed to improve the ability of students to use the internet as well as supervision so as not to be contaminated with negative content from the internet.
\end{abstract}

Keywords - Internet, teenagers, students with visually impaired, communication and information technology.

\section{Introduction}

The digital age has made the internet become an entity that is widely used in communication technology. The ease of communication, sharing and access to information, through the internet with various information communication technology devices that facilitate it, makes each individual try to adapt to the development of internet technology in order to obtain benefits that can be used to facilitate human activities. Digitizing public services makes people with disabilities be required to be able to use information technology such as who are not disabled [1], this is what drives people with disabilities to adapt.

However, even in 4.0 era, information can only be accessed in the form of text and images. This certainly makes it difficult for people with visual impairments to consume 
it. One of the factors that causes people with visual impairments is limited access to information, because most information is presented in visual form, both text and images. At the beginning of the emergence of communication technology media, people with visual impairments often need the help of others in operating gadgets or other communication technology media. For example, like developments in the world of mobile phones, when mobile phones still use the keypad there are aids that make it easier for people with visual impairments to identify and memorize the location of buttons on the keypad. However, the distance between the keys is too close and the typing system is not QWERTY based often become the cause of typing errors.

Especially when mobile phones have used touchscreen technology. The process of adaptation of people with visual impairments tends to have more severe challenges. In addition to the novelty factor that moves from pressing the keypad to touching, and sliding the screen, also because the QWERTY display on the touch screen keypad makes them have to begin to adapt and memorize the location of the letters on the keypad. However, along with the awareness of technology developers on the rights of people with visual impairments, a tool is made that makes it easy for people with visual impairments to access information in the form of text or some images. Screen Reader has become the main tool for people with visual impairments to use the internet [2]. However, there are still many obstacles experienced by people with visual impairments in accessing content even when assisted by a screen reader who is able to convert visuals into an audio format.

Even though there have been many people with visual impairments, especially students, who have used social media actively. This refers to data showing that, the level of use of social media by people with visual impairments is generally high, and the level of social media use is significantly related to age because younger people use social media more than parents [3]. This shows the tendency of internet usage, one of which is through social media by students with visual impairments.

This phenomenon certainly brings new things that need to be considered by the developers of communication technology, so that their products are able to accommodate the special needs of people with visual impairments with information communication technology. If in the past, things related to technology were things that were beyond the reach of the blind. Now many students with visual impairments have an interest in technology, especially its utilization. Research has shown that students with visual impairments are interested in new technology and even though at first they have not used it optimally. But towards the end of the situation changed, most students felt happy to study the subject about this new technology and also began to know the benefits of their personal and interpersonal developments that would be obtained if they were able to adapt to new technologies [4]

In principle, the internet not only helps them to carry out daily tasks, but also makes them feel socially inclusive. However, it is feared that the rapid advances in technology can also expand the digital divide if the obstacles experienced by people with visual impairments in accessing the internet are not resolved properly [5]. Especially if students with visual impairments already know a product, both tools and applications that can be utilized by non-disabled people, but the usability of people with visual impairments cannot be optimized due to the lack of accessibility to it. 
Access to public information is a right for all individuals including people with visual impairments. However, this is precisely the main problem for people with visual impairments to access information easily, due to limited resources that are in accordance with their specificity [6]. For example, in general, the process of delivering information / news through a website is only intended for people who have normal eyes, but there are still few websites that provide information / news for the visually impaired [7]. This is what directs this research to study more about internet use among students with visual impairments. Given that most students with visual impairments in research locations use smartphones that are able to access the internet both data plan credit and wifi based.

\section{$2 \quad$ Method}

This study used an open questionnaire as a research instrument that was disseminated to collect data on internet utilization by students with visual impairments. 41 respondents were taken from students who attended SLBN A (Special School for Blind), Bandung, located in the Wiyataguna Padjadjaran Bandung complex. By coincidence, Bandung City is a city which is a place where rehabilitation centers for the blind are located. So that in this school, students are generally students who not only come from the local area but also come from other cities, even from other provinces on different islands. Some students who come from the local area or outside the region, are students who come from families with middle economic level so that they are able to equip their children with communication facilities in the same class of smartphones to facilitate communication with family. The data collected through questionnaires, then calculated and classified for further analyzed descriptively as a conclusion. At the time of distributing the questionnaire, each respondent was asked by an enumerator who was in charge of reading out the questions and writing down the answers stated by the respondents. Results and Discussions

The internet is one proof of the development of civilization. Every individual has the right to relish the results of civilization. Including people with disabilities. During this time, the condition of disability was considered to be one of the factors that prevented them from enjoying technological convenience, including utilizing various uses of the internet.

There are data which mention that more than one billion people including children (or around $15 \%$ of the world population) are estimated to live with disabilities. The lack of support services can make people with disabilities very dependent on their families, which prevents them from being economically and socially active [8], therefore many parties are moved to offer the help and support they need to achieve a good quality of life and enable them to participate in social and economic life. One of the parties that were moved to provide support to people with disabilities is technology developers.

Today, there are much software circulating specifically created for people with visual impairments to help them carry out their activities through the help of a device called a screen reader and speech synthesizer. The way that the software does is by changing the visual appearance to audio. But before being able to use this program 
through a computer, people with visual impairments should master braille, and smoothly type ten fingers [9]. One program that helps people with visual impairments to use computers is the JAWS program.

There is a research result which states that in general, respondents' perceptions of the user-interface in the JAWS program are positive. This can be seen from the answers of respondents who thought that the clarity of intonation and pronunciation of words from the JAWS program itself was quite clear, they also understood the words/instructions that could guide them when accessing information from the JAWS program. The help facilities in the JAWS program are also quite popular with users [10]. This means that JAWS is a program that makes it easy for people with visual impairments to use computer technology. Especially with the addition of the Indonesian language, which can be downloaded, making people with visual impairments find it easier to learn, because the language used is easier to understand [11]. The development of access to computers for people with visual impairments through the findings of various programs further opens up opportunities for people with visual impairments to get to know the internet.

In the digital era like now, every individual can connect with various parties by means of internet assistance. As individuals who are at the time of searching for identity and self-development, students are referred to as one of the active internet users. Including students who experience vision problems.

Based on the results of observations of a number of students who attend SLBN A specifically for the visually impaired, there are many students who are in their teens, many have used smartphones. One of the benefits of a smartphone that is considered to support its activities is the ease of accessing the internet. Referring to the results of data collection, which was collected from the answers to the questionnaire, answers were obtained from 41 students who were classified as students providing answers about the use of the internet both accessed through smartphones or other devices such as computers. Their answers are illustrated in the following picture:

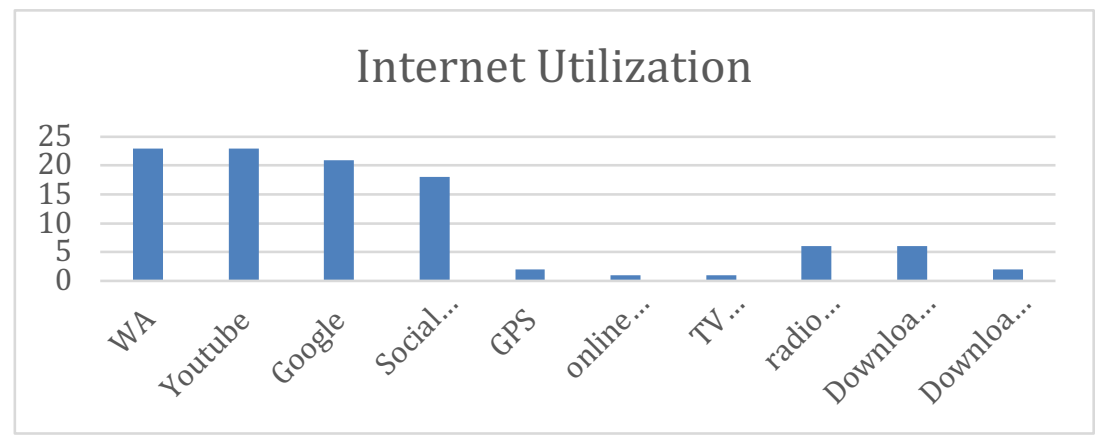

Fig. 1. Internet utilization by students with visual impairments

Data shows that students with visual impairments use the internet to download videos and music. As proof, students with visual impairments who are respondents are known to have a large collection of songs, both Indonesian and foreign, in their 
smartphone memory. The results of downloading music are used to memorize song lyrics and vocal tones and musical instruments because some of them are also known to have music extracurricular activities at school. Likewise, with radio streaming, it is usually used to listen to songs from their favorite radio.

Meanwhile, for TV streaming purposes, most are used to listen to the shows of their favorite club football matches or listen to the soap opera stripping they like. The average GPS and online shop is used by students with visual impairments who have a higher technological capability than the peer group, because so far it has been known that there have been many visual impairments communities of technology lovers who are members of a community like ICT for visually impaired, which is a place to share information about the latest communication technology that is relevant to their disability condition.

Other findings indicate that the symptoms of interaction and communication of students with visual impairments began to move using internet-based media. Based on these data, it is known that the internet uses to open WhatsApp both through direct message and group, occupying the top position. Followed by access to social media in third place. Social media such as Facebook, and Instagram, are the types of social media that are most frequently mentioned by respondents. Social media as a social networking site has the potential to empower people with disabilities. This is in line with a finding showing that 172 people with disabilities who responded to survey research using Facebook as did other people in general, meant they had no difficulty interacting in cyberspace such as Facebook. However, it was also stated that they have not used Facebook's potential to promote advocacy activities through disability empowerment groups [12]

In contrast to the results of previous research findings, which took disability samples of various types, there were results which stated that 100 blind users, noted their difficulties in using the Web. The reported obstacles are (a) the page layout that causes feedback mismatches from the screen reader; (B) conflict between screen reader and application; (c) non-labeled forms; (d) no alt text for images; and (e) between inappropriate links, inaccessible PDFs, and jammed screen reader tabs. Most of the causes of obstacles, such as inappropriate shapes and confusing graphics labels and page layouts, are relatively easy to solve if Webmasters and Web designers focus on improving efforts in this regard [13]. There is research that reveals the obstacles experienced by people with visual impairments in the use of computers related to accessing information in the form of images. Those who argue that alt text standards, have not utilized the capabilities of modern computing technology that can be used to provide adequate, immersive, and appropriate digital image information for the visual impaired [14].

In the world of education, the internet has become a difficult thing to ignore. There are many learning media that are packaged in the form of communication technology. Moreover, there is a government program that starts directing school-based smart schools that are loaded with technological needs that are accessible to the conditions of students with visual impairments.

Therefore, in the issue of inclusive education for people with censorship, motor, and mild cognitive impairment, it is better to consider the problem of the needs of these 
people to provide technological solutions that are appropriate to their conditions [15]. In this regard, devices and systems have been designed and developed that consider the utility, costs, and needs of this technology. Several technologies have been delivered to various institutions involved and have concerns about the issue of people with special abilities. These institutions have actively assisted and evaluated the technology developed. Therefore there are many development tools and software that are devoted to helping the visually impaired information and technology. One of them is illustrated in a study that illustrates how virtual reality technology can be used to address information technology problems from people whose vision is impaired [16]

Thus the advice for developers and producers of social media is to arrange a layout that is better or simpler [17], so that it is easy to use for people with visual impairments. In addition, it is expected that designers in information technology can consider designs that will be able to improve social networks for all users, including people with disabilities [18], so that teenagers with visual impairments will be able to use this media to develop themselves.

Along with the development of the internet, it is also necessary to consider the supervision of negative content for teenagers with visual impairments. Considering that the safe search program launched by the government is still limited to the Google application, but it has not yet penetrated other applications which are also indicated to have the opportunity to spread negative content. Since YouTube is an application that is widely accessed by teenagers with visual impairments, supervision is needed to prevent contamination of pornographic content that can be intentionally or inadvertently accessed and accessed by teenagers with visual impairments. Although so far the respondents have stated that accessing YouTube is intended to search for videos that contain information or entertainment that are still within reasonable limits. To compensate for the accelerated development of technology, it is necessary to increase the knowledge and skills of parents and teachers as supervisors about the use of technology by children and students who experience disabilities through training programs and seminars [19], although the emergence and progress of technology has been successfully applied in the field of teaching [20], but still requires supervision in its use to avoid the adverse effects of this information technology.

In addition to monitoring content, it is also necessary to monitor the intensity of internet use, because it is feared that a sense of dependence on teenagers with visual impairments who are lulled by the existence of smartphones and the internet will be neglected to environmental conditions and conditions. Because when observations are also known there is anxiety that appears to some respondents when the smartphone cannot be used because it runs out of batteries, runs out of quota, or technical problems. This anxiety is feared to indicate their dependence on smartphones.

The need for teenagers with visual impairments on smartphones and the internet usually tends to increase when they are in an inclusive environment when they are among ordinary people, who often make them feel different and neglected in interactive activities. Therefore it is necessary to supervise and provide understanding by adults who are around the teenagers with visual impairments to themselves (the teenagers with visual impairments) or to the alert environment around the teenagers with visual 
impairments so not cause alienation that affects solitaire attitudes that arise in the teenagers with visual impairments.

\section{Conclusion}

Based on the results of the processed data, it can be concluded that the use of the internet by students with visually impaired in sequence includes: WhatsApp, YouTube, Google, Social Media (Facebook and Instagram), radio streaming, video downloads, music downloads, Map/location identifier, online shop, and streaming TV to watch football shows. The use of the internet is based on the need to communicate, find information, and entertain. The internet access is used to access files in the form of audio, visual, or text with the help of a number of applications that are able to convert text into audio, according to the ability of people with visually impaired who have limited vision. As for files that are still in the form of text or static images such as photos and voiceless images that are accessed by visually impaired teenagers, they are usually accessed by those who still have the remnant vision or low vision. Therefore it takes a harder effort from the technology developer to be willing to develop communication technology products that provide equal opportunities to the people with visually impaired in using the internet. This effort can also be encouraged by advocacy activities from related parties to connect between the needs of people with visually impaired for communication technology with the developer by proposing some of the needs of people with visually impaired who have identified solutions.

\section{$4 \quad$ References}

[1] B. A. Shawar, "Evaluating web accessibility of educational websites," Int. J. Emerg. Technol. Learn., vol. 10, no. 4, pp. 4-10, 2015. https://doi.org/10.3991/ijet.v10i4.4518

[2] P. Verma, R. Singh, and A. K. Singh, "A Framework for the Next Generation Screen Readers for Visually Impaired," Int. J. Comput. Appl., vol. 47, no. 10, pp. 31-38, 2012. https://doi.org/10.5120/7226-0063

[3] J. T. Morris, J. L. Mueller, and M. L. Jones, "Use of Social Media During Public Emergencies by People with Disabilities," West. J. Emerg. Med., vol. XV, no. 5, pp. 567574, 2014. https://doi.org/10.5811/westjem.2014.4.21274

[4] M.-E. Osiceanu and I. Popa, "Access Technologies (AT) for Students with Visual Impairments," Procedia - Soc. Behav. Sci., vol. 180, no. November 2014, pp. 1129-1136, 2015. https://doi.org/10.1016/j.sbspro.2015.02.226

[5] P. Okonji, M. Lhussier, C. Bailey, and M. Cattan, "Internet use: Perceptions and experiences of visually impaired older adults," J. Soc. Incl., vol. 6, no. 1, pp. 120-145, 2015.

[6] N. Yurtay, Y. Yurtay, and M. F. Adak, "An Education Portal for Visually Impaired," Procedia - Soc. Behav. Sci., vol. 171, pp. 1097-1105, 2015. https://doi.org/10.1 016/j.sbspro.2015.01.271

[7] A. Septianto and F. R. Purba, "Perancangan dan implementasi portal berita untuk tuna netra menggunakan PHP V5.3.1,” J. Tek. dan Ilmu Komput., vol. 2, no. 6, pp. 200-209, 2013.

[8] M. C. Domingo, "An overview of the Internet of Things for people with disabilities," $J$. Netw. Comput. Appl., vol. 35, no. 2, pp. 584-596, 2012. 
[9] E. Baharudin, "Pemanfaatan software untuk tunanetra dalam menggunakan komputer," $J$. FASILKOM, vol. 4, no. 2, pp. 122-127, 2006.

[10] R. Sapputra, "Persepsi Siswa Tunanetra Tentang Program Jaws Di Fakultas Ilmu Pendidikan Universitas Negeri Padang," E-JUPEKhu (Jurnal Ilm. Pendidik. Khusus), vol. 1, no. 3, pp. 688-499, 2015. https://doi.org/10.30596/bibliocouns.vli1.1941

[11] E. Priyadi, "Analisis aplikasi talkback bagi penyandang tunanetra pada operasi sistem android," Dok. Karya Ilm. Univ. Dian Nuswantoro Semarang, 2014.

[12] C. Shpigelman and C. J. Gill, "Facebook Use by Persons with Disabilities," J. Comput. Mediat. Commun., vol. 19, pp. 610-624, 2014. https://doi.org/10.1111/jcc4.12059

[13] J. Lazar, A. Allen, J. Kleinman, and C. Malarkey, "What Frustrates Screen Reader Users on the Web : A Study of 100 Blind Users What Frustrates Screen Reader Users on the Web : A Study of 100 Blind Users," Int. J. Human-Computer Interact., vol. 22, no. 3, pp. 247-269, 2007. https://doi.org/10.1080/10447310709336964

[14] M. R. Morris, J. Johnson, C. L. Bennett, and E. Cutrell, "Rich Representations of Visual Content for Screen Reader Users," Proc. 2018 CHI Conf. Hum. Factors Comput. Syst., 2018. https://doi.org/10.1145/3173574.3173633

[15] A. M. Echenique et al., "Inclusive Educative Technologies, for people with disabilities," $J$. Phys. Conf. Ser., vol. 705, pp. 1-10, 2016.

[16] N. I. Ghali et al., "Virtual Reality Technology for Blind and Visual Impaired People: Reviews and Recent Advances," Intell. Syst. Ref. Libr., vol. 26, pp. 363-385, 2012.

[17] J. Asuncion, J. Budd, C. S. Fichten, M. Nguyen, M. Barile, and R. Amsel, "Social Media Use By Students With Disabilities," Acad. Exch. Q., vol. 16, no. 1, p. 30-35, Editor's Choice, 2012.

[18] V. Voykinska, S. Azenkot, S. Wu, and G. Leshed, "How blind people interact with visual content on social networking services," CSCW'16 Proc. 19th ACM Conf. Comput. Coop. Work Soc. Comput., pp. 1584-1595, 2016. https://doi.org/10.1145/2818048.2820013

[19] B. Baglama, M. Haksiz, and H. Uzunboylu, "Technologies Used in Education of Hearing Impaired Individuals," Int. J. Emerg. Technol. Learn., vol. 13, no. 9, pp. 53-63, 2018. https://doi.org/10.3991/ijet.v13i09.8303

[20] Z. Yu, "Development and Implementation of Touch Screen Multimedia Technology in Sports Physiology Curriculum," Int. J. Emerg. Technol. Learn., vol. 11, no. 1, pp. 21-25, 2016. https://doi.org/10.3991/ijet.v11i01.5144

\section{Authors}

Hanny Hafiar, is a lecturer at the Universitas Padjadjaran, Bandung, Indonesia. She is a researcher who has the concentration on topics related to disability and active in conducting socialization regarding disability to early childhood.

Priyo Subekti, is lecturer in public relations study program, Faculty of Communication Science, Universitas Padjadjaran, Bandung, Indonesia. Currently active as the editor of the accredited journal at Universitas Padjadjaran.

Aat Ruchiat Nugraha, is a lecturer at Universitas Padjadjaran, Bandung, Indonesia and also a member of the Association of the Indonesian Communication Science Journal Manager (APJIKI).

Article submitted 2018-12-28. Resubmitted 2019-01-28. Final acceptance 2019-01-28. Final version published as submitted by the authors. 